\title{
Potrditev prisotnosti plenilske hržice Feltiella acarisuga (Vallot, 1827) in plenilskega kratkokrilca Oligota oviformis Casey, 1893 na navadni pršici (Tetranychus urticae Koch, 1836) v Sloveniji
}

\author{
Katarina $\mathrm{KOS}^{1}$, Franci Aco CELAR ${ }^{2}$
}

Received December 01, 2017; accepted March 26, 2018.

Delo je prispelo 01. decembra 2017, sprejeto 26. marca 2018.

\section{IZVLEČEK}

Navadna pršica, Tetranychus urticae C. L. Koch, 1836 je eden najpomembnejših škodljivcev zavarovanih prostorov pri nas in $\mathrm{v}$ svetu. Zaradi svoje polifagnosti in hitrega razmnoževanja so populacije pršic velike, zato ima tudi veliko naravnih sovražnikov, ki jih lahko uporabimo v biotičnem varstvu proti temu škodljivcu. Poleg številnih plenilskih pršic (Phytoseiulus persimilis Athias-Henriot, 1957, Amblyseius swirskii AthiasHenriot, $1962, \ldots$ ) je izredno uspešen plenilec navadne pršice tudi plenilska hržica Feltiella acarisuga (Vallot, 1827), ki smo jo v letu 2017 množično zasledili v rastlinjaku Biotehniške fakultete v Ljubljani na jajčevcu sorte 'Matrona'. Poleg plenilske hržice smo zaznali tudi veliko število plenilskih hroščev kratkokrilcev in njihovih ličink iz družine Staphylinidae, vrsta Oligota oviformis Casey, 1893 Vrsto $F$. acarisuga se lahko tudi uvrsti na seznam domorodnih vrst organizmov in se jo uporablja $\mathrm{v}$ biotičnem varstvu, saj je $\mathrm{v}$ tujini že vrsto let med vodilnimi organizmi za varstvo gojenih rastlin pred pršicami.

Ključne besede: biotično varstvo; Feltiella acarisuga; Oligota oviformis; Tetranychus urticae; zavarovani prostor

\author{
ABSTRACT \\ CONFIRMATION OF PRESENCE OF A PREDATORY \\ GALL MIDGE, Feltiella acarisuga, (Vallot, 1827) AND \\ STAPHYLINID PREDATOR Oligota oviformis Casey, \\ 1893 OF A TWO SPOTTED SPIDER MITE (Tetranychus \\ urticae, Koch, 1836) IN SLOVENIA
}

The two spotted spider mite, Tetranychus urticae C. L. Koch, 1836 is one of the most important pests of greenhouse crops worldwide. Due to its polyphagic range of hosts and rapid development it forms great populations and as such represents a suitable host/prey for lots of natural enemies usable in biological control. Most commonly used predators of Tetranychid mites are predatory mites (Phytoseiulus persimilis Athias-Henriot, 1957, Amblyseius swirskii Athias-Henriot, $1962, \ldots)$, but among most voracious predators is the larva of a predatory gall midge, Feltiella acarisuga (Vallot, 1827) that was found also in greenhouses of the Biotechnical Faculty in Ljubljana on eggplant leaves in 2017. Besides the predatory gall midge also another predator, staphylinid Oligota oviformis Casey, 1893 beetles and larvae were found in great numbers. After positive identification of $F$. acarisuga found naturally in Slovenia, it can be added to the list of indigenous species of natural enemies and thus can be used in biological control programs in greenhouse crop protection against spider mites.

Key words: biological control; Feltiella acarisuga; greenhouse; Oligota oviformis; Tetranychus urticae

\section{UVOD}

Navadna (fižolova ali hmeljeva) pršica Tetranychus urticae Koch, 1836 (Acari, Tetranychidae) je eden najpomembnejših škodljivcev gojenih rastlin $\mathrm{v}$ zavarovanih prostorih in na prostem (Opit in sod.,
2004). Tako odrasli osebki kot tudi nimfe se s sesanjem hranijo na rastlinah in povzročajo večjo škodo. Hiter razvoj, velik razmnoževalni potencial in pogosta raba akaricidov vodijo do hitrega razvoja odpornosti na

1 Doc. dr., Univerza v Ljubljani, Biotehniška fakulteta, Oddelek za agronomijo, Jamnikarjeva 101, SI-1111 Ljubljana, Slovenija, e-mail: katarina.kos@bf.uni-lj.si

2 Prof. dr., Univerza v Ljubljani, Biotehniška fakulteta, Oddelek za agronomijo, Jamnikarjeva 101, SI-1111 Ljubljana, Slovenija, e-mail: franci.celar@bf.uni-lj.si 
fitofarmacevtska sredstva (Xiao in sod., 2013). Biotično varstvo je alternativna možnost omejevanja populacij škodljivih organizmov z uporabo naravnih sovražnikov. Poleg plenilskih pršic, ki lahko zmanjšajo populacije navadne pršice (Amano, 2001; Escudero in Ferragut, 2005), so izredno učinkovite tudi plenilske žuželke, še posebej se izpostavlja plenilsko hržico Feltiella acarisuga (Vallot, 1827), ki je tudi tržno dostopna (Gagné, 1995). Pogosto se omenja štiri rodove plenilskih žuželk, in sicer Oligota (Coleoptera: Staphylinidae), Stethorus (Coleoptera: Coccinellidae), Scolothrips (Thysanoptera, Thripidae) in Feltiella (Diptera; Cecidomyiidae), ki uspešno plenijo navadno pršico (Abe in sod., 2011; Shimoda in sod. 2015). Dva od njih, Stethorus in Feltiella sta tudi uvrščena na seznam tujerodnih vrst organizmov za biotično varstvo rastlin (UVHVVR, 2017).

V Sloveniji zakonodaja na področju varstva rastlin zahteva, da je za vnos in uporabo tujerodnih vrst organizmov na območju Republike Slovenije potrebno pridobiti dovoljenje Uprave za varno hrano, veterinarstvo in varstvo rastlin, ki se izda $\mathrm{v}$ soglasju $\mathrm{z}$ ministrstvom, pristojnim za ohranjanje narave (UVHVVR, 2017). Zato si prizadevamo najti in potrditi čim več organizmov iz seznama tujerodnih vrst, da so naravno prisotni na območju Slovenije in jih tako uvrstiti na Seznam domorodnih vrst, ki se jih lahko uporablja $\mathrm{v}$ okviru biotičnega varstva pri nas.

\subsection{Plenilska hržica Feltiella acarisuga (Vallot, 1827)}

Odrasla hržica meri do $2 \mathrm{~mm} v$ dolžino, ima svetlo rjavo do oranžno barvo telesa in dolge noge. Imago živi 12-14 dni in se hrani z nektarjem rastlin. Samica izleže okrog 33 drobnih prozornih jajčec $(0.25 \mathrm{~mm})$ iz katerih se razvijejo žerke, ki imajo 3 stopnje (se dvakrat levijo) in dosežejo dolžino do $3 \mathrm{~mm}$ ter so tipične rdečkastooranžne barve (Slika 1). Zabubijo se v svilen zapredek. Ličinke plenilske hržice so ene najpomembnejših naravnih sovražnikov navadne pršice in drugih pršic prelk iz družine Tetranychidae (Gagné, 1995; Osborne in sod., 2017).

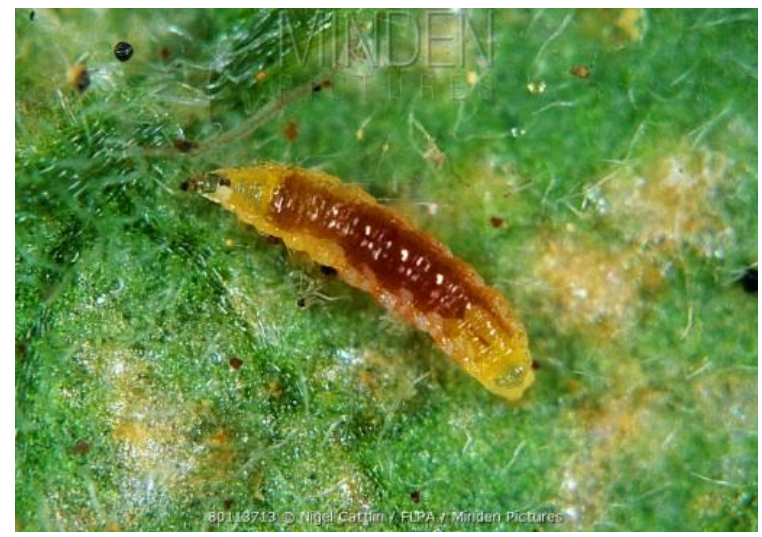

Slika 1: Žerka plenilske hržice (vir: https://www.mindenpictures.com/search/preview/predatory-midge-larve-fetiellaacarisuga-larva-red-after-feeding-on-red/0_80113713.html, 1.12.2017)

Figure 1: The predatory gall midge larva (source: https://www.mindenpictures.com/search/preview/predatorymidge-larve-fetiella-acarisuga-larva-red-after-feeding-on-red/0_80113713.html, 1.12.2017)

\subsection{Plenilski kratkokrilec Oligota oviformis (Casey, 1893)}

Vrsta $O$. oviformis pripada rodu Oligota, ki je majhna skupina kratkokrilcev iz poddružine Aleocharinae in zajema okoli 300 vrst. Vrste iz tega rodu so majhni hroščki, ki merijo povprečno le $1.0 \mathrm{~mm}$ (Williams, 1976). Vrsta O. oviformis je zanimiva, saj tako odrasli osebki kot tudi ličinke plenijo navadno pršico in so tako koristni z agronomskega stališča (Moore in sod., 1975). Imagi vrste $O$. oviformis so majhni hroščki črne barve z značilno kratkimi pokrovkami. Običajno hodijo $\mathrm{s}$ pokonci dvignjenim zadkom. Njihova ličinka je podolgovata, meri okoli $2.1 \mathrm{~mm}$ v dolžino in ima črno liso na osmem členu zadka (Slika 2). 


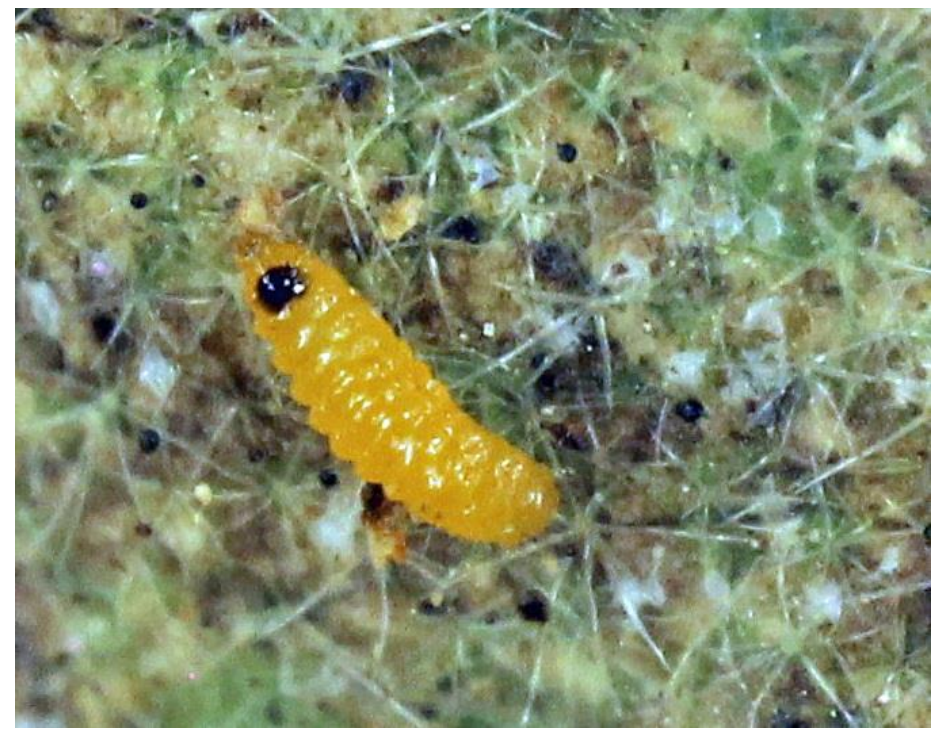

Slika 2: Ličinka vrste $O$. oviformis na listu jajčevca (foto F.A. Celar)

Figure 2: Predatory O. oviforms larva on eggplant leaf (photo F.A. Celar)

\section{MATERIALI IN METODE}

Konec meseca septembra 2017 smo v rastlinjakih Biotehniške fakultete v Ljubljani našli velike populacije navadne pršice na jajčevcu sorte 'Matrona' (Solanum melongena $\mathrm{L}$.). Napadene liste jajčevca smo pobrali in $\mathrm{v}$ laboratoriju s pomočjo stereolupe iskali morebitne naravne sovražnike (Olympus SZ30). Ličinke in odrasle osebke plenilskih hržic smo poslali $\mathrm{v}$ identifikacijo dr. Raymondu J. Gagné (Taxonomic Services Unit, USDAARS-Systematic Entomology Laboratory, ZDA), vrsto O. oviformis pa smo potrdili s pomočjo identifikacijskih ključev in opisov (Moore in sod., 1975; Williams, 1976).

\section{REZULTATI IN DISKUSIJA}

Na listih jajčevca smo našli številne plenilske žuželke. Med njimi so bile tudi ličinke in odrasli osebki plenilskih stenic (Orius sp.), vendar pa je bilo največ ličink plenilske hržice, vrste $F$. acarisuga, katero nam je potrdil tudi strokovnjak za identifikacijo hržic iz družine Cecidomyiidae dr. R.J. Gagné, in ličink ter odraslih osebkov kratkokrilcev $O$. oviformis. Plenilska hržica $F$. acarisuga velja, poleg na pršice specializirane plenilske polonice iz rodu Stethorus, za najpomembnejšo plenilko pršic prelk. Odrasle hržice so tudi dobre letalke, imajo dobro sposobnost iskanja plena in velik potencial hranjenja na vseh razvojnih stadijih pršic. Razširjene so po večini kontinentov (kozmopoliti), plenijo pa lahko tudi druge pršice prelke. V laboratorijskih poskusih so Xiao in sod. (2013) dokazali da so ličinke hržice $F$. acarisuga uničile tudi do 50 jajčec pršic na dan, medtem ko so jih plenilske pršice uničile približno pol manj $(25$ jajčec samice Phytoseiulus persimilis (Anthias-Henriot, 1957) in 15 Amblyseius swirskii (Anthias-Henriot, 1962)). Ravno na jajčevcu je Sharaf (1984) opazil naravno prisotnost plenilske hržice, ki je zmanjšala populacijo pršic tudi preko $40 \%$. Vsaka žerka naj bi zaužila dnevno vsaj 15 odraslih pršic, 30 različnih razvojnih stadijev nimf ali po 80 jajčec. Razvoj hržice se odvija pri temperaturnem razponu od $15-25{ }^{\circ} \mathrm{C}$. Jajčeca in ličinke so občutljive na visoke temperature (nad $30^{\circ} \mathrm{C}$ ) in suh zrak (relativna zračna vlaga pod $30 \%$ ). Optimalne razmere za njen razvoj so $20^{\circ} \mathrm{C}$ in $90 \%$ relativna zračna vlaga (Gillespie in sod. 1998).

V biotičnem varstvu je priporočljiva tudi kombinirana uporaba koristnih organizmov in pravočasen vnos. Ker je plenilska hržica leteča, lažje išče svoj plen na večje razdalje kot pa plenilske pršice (npr. P . persimilis), vendar je priporočljivo uporabiti obe vrsti hkrati, če je plena dovolj. Če plena primanjkuje pa lahko plenilske pršice plenijo tudi jajčeca hržice in tako zmanjšajo učinkovitost kombiniranega biotičnega varstva (Gillespie in sod., 1998). 


\section{SKLEPI}

Potrjujemo prisotnost dveh pomembnih plenilcev navadne pršice v Sloveniji, to sta plenilska hržica $F$. acarisuga in plenilski kratkokrilec O. oviformis. Obe vrsti sta bili močno zastopani in upamo, da nam bosta tudi $\mathrm{V}$ prihodnje pomagali pri omejevanju širjenja navadne pršice, oziroma pri zmanjševanju njenih populacij brez uporabe fitofarmacevtskih sredstev. Nepravilna in pogosta uporaba akaricidov lahko vodi do odpornosti pršic na tovrstna fitofarmacevtska sredstva. Naravni sovražniki nam lahko, ob pravočasni uporabi in v primernih razmerah, pomagajo, da na naraven način zatremo škodljivca in preprečimo razvoj odpornosti na akaricide. S pogosto uporabo insekticidov $\mathrm{s}$ širokim spektrom delovanja za zatiranje žuželk v rastlinjakih lahko močno zmanjšamo ali pa popolnoma uničimo favno občutljivih koristnih organizmov. Potrditev vrste $F$. acarisuga nam omogoča uvrstitev tega organizma na seznam domorodnih vrst koristnih organizmov v Sloveniji in njegovo uporabo, saj je v tujini že vrsto let tržno dostopen (Biobest, Koppert,...).

\section{ZAHVALA}

Najlepše se zahvaljujemo dr. Raymond J. Gagné (Taxonomic Services Unit, USDA-ARS-Systematic
Entomology Laboratory, ZDA) za identifikacijo plenilske hržice.

\section{VIRI}

Abe, J., Ganaha-Kikumura, T., \& Yukawa, J. (2011). Morphological features, distribution, prey mites, and life history traits of Feltiella acarisuga (Vallot) (Diptera: Cecidomyiidae) in Japan. Applied Entomology and Zoology, 46, 271-279. https://doi.org/10.1007/s13355-011-0038-X

Amano, H. (2001). Species structure and abundance of invertebrate natural enemies in sustainable agroecosystems. V: M. Shiyomi, H. Koizumi (Ur.), Structure and Function in Agroecosystem Design and Management, FL, USA (pp. 167-181) CRC Press LLC.

Escudero, L.A., \& Ferragut, F. (2005). Life-history of predatory mites Neoseiulus californicus and Phytoseiulus persimilis (Acari: Phytoseiidae) on four spider mite species as prey, with special reference to Tetranychus evansi (Acari: Tetranychidae). Biological Control, 32, 378-384. https://doi.org/10.1016/j.biocontrol.2004.12.010

Gagné, R.J. (1995). Revision of Tetranychid (Acarina) mite predators of the genus Feltiella (Diptera: Cecidomyiidae). Annals of the Entomological Society of America, 88, 16-30. https://doi.org/10.1093/aesa/88.1.16

Gillespie, D.R., Roitberg, B., Basalyga, E., Johnstone, M., Opit, G., Rodgers, J., \& Sawyer, N. (1998). Biology and application of Feltiella acarisuga (Vallot) (Diptera: Cecidomyiidae) for biological control of twospotted spider mites on greenhouse vegetable crops. Pacific Agri-Food Research Centre (Agassiz) Technical Report, No. 145. Agriculture and Agri-Food Canada.
Moore, I., Legner, E.F., \& Badgley, M.E. (1975). Description of the developmental stages of the mite predator, Oligota oviformis Casey, with notes on the osmeterium and its glands (Coleoptera: Staphylinidae). Psyche, 82, 181-188. https://doi.org/10.1155/1975/67561

Opit, G.P., Roitberg, B., \& Gillespie, D.R. (1997). The functional response and prey preference of Feltiella acarisuga (Vallot) (Diptera: Cecidomiidae) for two of its prey: male and female two-spotted spider mites, Tetranychus urticae Koch (Acari: Tetranychiidae). Canadian Entomologist,129, 221227. https://doi.org/10.4039/Ent129221-2

Opit, G.P., Nechols, J.R., \& Margolies, D.C. (2004). Biological control of twospotted spider mites, Tetranychus urticae Koch (Acari: Tetranychidae), using Phytoseiulus persimilis Athias-Henriot (Acari: Phytoseidae) on ivy geranium: assessment of predator release ratios. Biological Control, 29, 445-452. https://doi.org/10.1016/j.biocontrol.2003.08.007

Osborne, R.S., Kumar, V., Leppla, N., \& Osborne, L.S. (2016). Predatory gall midge (unofficial common name) scientific name: Feltiella acarisuga (Vallot) (Insecta: Diptera: Cecidomyiidae). http://entnemdept.ufl.edu/creatures/beneficial/f_aca risuga.htm

Sharaf, N.S. (1984). Studies on natural enemies of tetranychid mites infesting eggplant in the Jordan Valley. Zeitschrift für Angewandte Entomologie, 98, 527-533. https://doi.org/10.1111/j.14390418.1984.tb02745.x 
Potrditev prisotnosti plenilske hržice Feltiella acarisuga ... na navadni pršici (Tetranychus urticae Koch, 1836) v Sloveniji

Shimoda, T., Kobori, Y., Yara, K., \& Hinomoto, N. (2015). A simple method of rearing insect natural enemies of spider mites. Biological Control, 80, 7076. https://doi.org/10.1111/j.14390418.1984.tb02745.x

UVHVVR. 2017. Seznam tujerodnih vrst organizmov za biotično varstvo rastlin. http://www.uvhvvr.gov.si/fileadmin/uvhvvr.gov.si/ pageuploads/DELOVNA_PODROCJA/Zdravje_ras tlin/2013/Bioticno_varstvo_rastlin/tujerodni_organi zmi/Seznam_tujerodnih_23_maj_2017_NOVO.pdf
Willims, S.A. (1976). The genus Oligota (Coleoptera: Staphylinidae) in New Zeland. New Zeland Journal of Zoology, 3(3), 247-255. https://doi.org/10.1080/03014223.1976.9517914

Xiao, Y., Osborne, L.S., Chen, J., \& McKenzie, C.L. (2013). Functional Responses and Prey-Stage Preferences of a Predatory Gall Midge and Two Predacious Mites with Twospotted Spider Mites, Tetranychus Urticae, as Host. Journal of Insect Science, $13(8)$, 1-12. https://doi.org/10.1673/031.013.0801 